\title{
A ESCOLHA PELA LICENCIATURA EM FÍSICA - UMA ANÁLISE A PARTIR DA TEORIA DA RELAÇÃO COM O SABER
}

\begin{abstract}
RESUMO: Este trabalho apresenta resultados de uma pesquisa sobre as relações dos licenciandos em física com o "ensinar". Tem-se como objetivo identificar quais os mediadores da escolha pela licenciatura em física, verificando como os saberes escolares interferiram nesta escolha. Utiliza-se como referencial teórico a Teoria da Relação com o Saber, desenvolvida por Bernard Charlot. A ferramenta metodológica utilizada foi um questionário com vinte questões, onde 83 foram retidos para análise. Através dos próprios argumentos evocados nas respostas foi construída uma grade de categorização e, através dela, calcularam-se percentuais para os argumentos mais citados pelos estudantes. Neste trabalho, analisaram-se as questões pertencentes ao bloco de perguntas "Eu e o que me levou a cursar a licenciatura em física". Os principais resultados apontam a escolha da licenciatura em física como carreira devido ao estabelecimento de uma forte relação com a física e a matemática escolar; relações positivas com escolha pela licenciatura, embora sem evidências de como essas relações foram estabelecidas.
\end{abstract}

Palavras-chave: Licenciandos em física, Mediadores da escolha pela licenciatura em física, Saberes Adquiridos na Escola, Teoria da Relação com Saber.

\section{THE CHOICE OF THE DEGREE IN PHYSICS LICENCIATE - AN ANALYSIS BASED ON THEORY OF RELATIONSHIP WITH KNOWLEDGE}

ABSTRACT: This paper presents results of a research that deals with the relationships of undergraduate students in physics with the idea of "teaching". The objective of this work is to identify which factors influence the students' choice to major in Physics teaching, by verifying how the acquired knowledge in school interfered this choice. The theoretical basis was the Theory of Relationship with Learning, developed by Bernard Charlot. The methodology tool used was the application of a questionnaire, with twenty questions, with eighty-three being retained for analysis. With the arguments present in the responses a grid of categorization was constructed and, with it, percentages were calculated for the arguments most often mentioned by the students. This work focused on the analysis of the questions belonging to the block of queries, "I and what led me to attend a degree to teach Physics." The main results show the choice of degree in physics as a career due to the establishment of a strong relationship with physics and mathematics in school; positive relationships with choice of becoming a physics teacher. However, no evidence of how these relationships has been established.

Keywords: Physics teacher students, Mediators of choice for the degree in physics, Knowledge Acquired at School, Theory of Relationship with Knowledge.
Larissa Dias Feitosa*

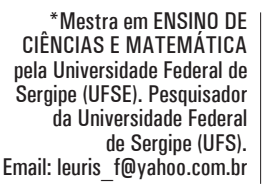

*Mestra em ENSINO DE pela Universidade Federal de Sergipe (UFSE). Pesquisador de Sergipe (UFS)

Email: leuris_f@yahoo.com.br 


\section{INTRODUÇÃO}

Certos indivíduos, jovens e adultos, têm o desejo de aprender algo, outros não. Apesar de muitos objetos de desejo serem compartilhados, o querer aprender é individual. Então, o questionamento principal a esse respeito seria descobrir o que motiva o interesse do indivíduo por este ou por aquele determinado tipo de saber?

Este trabalho apresenta resultados de uma pesquisa que procurou entender essa problemática. Ela trata das relações dos alunos da licenciatura em Física da Universidade Federal de Sergipe com o "ensinar". Suas perguntas norteadoras foram: "O que motiva ou desperta o desejo de um jovem licenciando pelo ensino de Física?" " "Qual a relação que esse jovem estabelece com o ensinar?”.

Utilizou-se como referencial teórico para fazer essa análise a teoria da relação com o saber, desenvolvida por Bernard Charlot no decorrer de suas obras (CHARLOT, 2000, 2001, 2005 e 2009). Essa teoria procura estudar as relações das pessoas com lugares, com outras pessoas e consigo mesmas, objetos, conteúdos de pensamento, situações, normas relacionais, etc., visto que está em jogo a questão do aprender e do saber (CHARLO'T, 2000).

Trata-se de uma pesquisa quantitativa e qualitativa, cuja ferramenta metodológica foi a aplicação de um questionário aberto, com um total de vinte questões. Foram retidos 83 questionários para análise. Com os argumentos evocados nas respostas, foi construída uma grade de categorização e, por meio dela, foram calculados percentuais para os argumentos mais citados pelos estudantes. Para uma análise mais aprofundada dos dados obtidos neste trabalho, foram analisadas as questões pertencentes ao bloco de perguntas "Eu e o que me levou a cursar a licenciatura em Física".

\section{SOBRE A TEORIA DA RELAC̣ÃO COM O SABER}

O homem está condicionado, desde o seu nascimento, ao aprender. Aprender significa, para o menino-homem, inserir-se em um mundo que o pré-existia e que traz consigo uma série de saberes a serem adquiridos. Nesse movimento complexo, e sempre inacabado, de construir-se por meio da relação consigo mesmo, com os outros e com o mundo, surge o desejo de aprender. É esse desejo que impulsiona o homem ao ato de aprender para que ele caminhe em direção ao saber; é ele que chama o indivíduo, que o coloca na direção do que o atrai, concretizando-o através da interiorização do que era uma simples realidade externa.

Para se entender a lógica da busca por determinado saber, é preciso adentrar na singularidade do indivíduo, do que para ele vale a pena ser estudado, quais são as lógicas sociais, culturais que norteiam e estruturam sua atividade (Silva, 2009).

Faz-se necessário, para uma melhor compreensão da teoria da relação com o saber, apresentar os conceitos acerca de mobilização, atividade e sentido - sendo que estes se interpenetram no processo de escolarização: "para haver atividade, 
a criança deve mobilizar-se; para que se mobilize, a situação deve apresentar um significado para ela" (CHARLOT, 2000, p. 54).

A mobilização enfatiza a questão do movimento. "Mobilizar-se é pôr-se em movimento”, é acionar recursos; é tanto preliminar à ação, quanto ao seu primeiro momento. Colocar o nome do autor Charlot? opõe, ainda, a noção de mobilização à de motivação. Motiva-se o outro de fora enquanto mobiliza-se a si mesmo de dentro. Ou seja, o processo de apropriação do saber pertence, inevitavelmente, ao sujeito mobilizado. Muitas vezes professores tentam motivar o aluno para que ele faça algo alheio a sua vontade; em um aluno mobilizado, ocorre o despertar de um desejo no próprio aluno, um desejo que continua existindo quando o professor já não está.

Com base nas pesquisas de Rochex (1995, apud CHARLOT, 2000) e Leontiev (1975, apud CHARLOT, 2000) Charlot define atividade como "um conjunto de ações propulsionadas por um móbil e que visam a uma meta" (CHARLOT, 2000, p. 55). A definição de sentido, central nas pesquisas realizadas pela ESCOL ${ }^{1}$, considera três aspectos, dentre os quais se destaca o que é significante, ou, tem sentido, o que produz inteligibilidade sobre algo, o que aclara algo no mundo.

Ou, ainda, "esse sentido é um sentido para alguém que é um sujeito" (CHARLOT, 2000, p.56). Como consequência, deve-se, necessariamente, introduzir a dimensão do desejo: "pode-se dizer que fazem sentido um ato, um acontecimento, uma situação que se inscrevam nesse nó de desejos que o sujeito é” (p. 67).

Além disso, há que se compreender a distinção entre sentido como desejabilidade, isto é, que implica em valor, negativo ou positivo, e sentido como significação (Charlot, 2000, p.57). O que tem sentido sempre deve ter uma significação. Quando algo tem sentido para o sujeito ele está indicando que dá importância e valor a esse algo. Mas, o que tem uma significação nem sempre tem um valor para o sujeito. O sujeito pode entender do que se trata, mas isso não implica em valor para ele, nem de forma positiva, nem negativa. Ou seja, o que induz a atividade é o que tem um valor positivo para o sujeito. Só o que tem um valor positivo (desejável) pode mobilizar o sujeito para aprender. O que possui valor negativo também pode mobilizar o sujeito, só que para fugir da aprendizagem de um saber específico que não o interessa.

Vale destacar, também, que a questão do sentido não está definida de uma vez por todas. Algo pode adquirir sentido, perder sentido, mudar de sentido, pois o próprio sujeito evolui, por sua dinâmica própria e por seu confronto com os outros e com o mundo (CHARLOT, 2000, p.57).

Verificou-se o conceito da relação com o saber como sendo a relação de um sujeito com o mundo, com ele mesmo e com os outros; como uma relação com o mundo como conjunto de significados, mas também como espaço de atividades, e que se inscreve no tempo (CHARLOT, 2000, p. 78). A partir desses pressupostos, é possível saber o que se deve considerar quando se propõe uma investigação a respeito da relação de sujeitos com o "ensinar Física". 
Para cumprir os objetivos estabelecidos para essa investigação, deve-se considerar o sujeito, suas relações com outros sujeitos, com uma história única, articulada com a de uma família, de uma sociedade, da própria espécie humana, pertencente a um mundo no qual ocupa uma posição e onde se inscreve em relações sociais. Dessa forma, neste trabalho, pretende-se verificar de que forma o conjunto de relações e saberes adquiridos a partir das atividades escolares interferiram na escolha dos licenciandos pela licenciatura e pela Física na universidade.

\section{SUJEITOS E METODOLOGIA DE PESQUISA}

Os sujeitos de pesquisa são os alunos do curso de licenciatura em Física da Universidade Federal de Sergipe, nos campi de São Cristóvão e Itabaiana. Trata-se de uma pesquisa de caráter quantitativo e qualitativo, cuja ferramenta metodológica foi a aplicação de um questionário aberto, com um total de vinte questões. Foram retidos 83 questionários para análise.

Neste trabalho, nos ateremos a discutir os seguintes questionamentos:

04 - (a) No Ensino Médio, a Física para mim era...

(b) E a Matemática era...

05 - (a) Ao prestar o concurso vestibular, escolhi o curso de Física porque...

(b) E o que me levou a optar pelo curso de licenciatura foi...

06 - (a) Em relação ao curso, as minhas expectativas antes do início da graduação eram...

(b) E agora, em relação ao que esperava do curso, penso que...

Com os argumentos evocados nas respostas, foi construída uma grade de categorização e, por meio dela, foram calculados os percentuais para os argumentos mais citados pelos estudantes. A construção da grade para categorizar as respostas, de cunho qualitativo, foi inspirada nas metodologias utilizadas por Charlot (2009) em sua investigação acerca da relação com o saber dos estudantes dos liceus profissionalizantes dos subúrbios franceses e na pesquisa de Silva (2009) acerca da relação com o saber matemático de alunos do Ensino Fundamental em escolas da periferia de São Cristóvão, Sergipe.

Charlot (2009) utilizou como instrumento metodológico de coleta de dados os "balanços de saber". Estes têm por objetivo incitar os alunos a elaborarem um texto a partir da seguinte premissa: "Desde que nasci aprendi muitas coisas em minha casa, no bairro, na escola, em outros lugares... O quê? Com quem? Em tudo isto, o que é mais importante para mim? E agora, de que é que estou à espera?"

A partir dos argumentos evocados nos balanços de saber, Charlot construiu seu instrumento de análise metodológica, que foram as grades de categorização. O autor chama atenção para o fato de que todo trabalho de categorização corresponde, inevitavelmente, a um trabalho de interpretação do pesquisador. Para que as respostas façam sentido, é necessário reagrupálas, categorizá-las, o que supõe que é preciso fazer escolhas - de forma que 
a categorização está igualmente ligada à relação com o saber do próprio pesquisador (CHARLO'T, 2009, p. 19).

Já Silva, 2009, utilizou como instrumento de coleta de dados um questionário aberto com catorze questões. Porém, seu instrumento de análise fora construído como proposto por Charlot (2009), pois consistiu na construção de grades de categorização para cada uma das questões propostas por meio da reagrupação dos argumentos evocados nas próprias respostas.

\section{O QUE OS LICENCIANDOS EM FÍSICA PENSAM A RESPEITO DA FÍSICA E DA MATEMÁTICA NO ENSINO MÉDIO}

A seguir, são apresentados os números obtidos para os questionamentos sobre a representação da Física e da Matemática construída pelos licenciandos quando se encontravam em época escolar. Fez-se questão de citar a Matemática no questionário, pois se sabe da forte relação entre as duas ciências no Ensino Médio e, principalmente, no Ensino Superior. Os resultados obtidos podem ser visualizados nas tabelas 1 e 2 .

Tabela 1: Resultados 04a

\begin{tabular}{|c|c|c|c|}
\hline \multicolumn{4}{|c|}{ Q4a - No Ensino Médio a Física era para mim... } \\
\hline Argumentos Centrais & Homens & Mulheres & Total \\
\hline $\begin{array}{c}\text { C1. A que mais desperta o interesse ou a } \\
\text { curiosidade/que mais atrai/que o aluno se } \\
\text { identifica ou gosta de estudar }\end{array}$ & $61 \%$ & $65 \%$ & $62 \%$ \\
\hline C2. Vida escolar & $17 \%$ & $14 \%$ & $16 \%$ \\
\hline C3. Relações negativas & $10 \%$ & $11 \%$ & $10 \%$ \\
\hline C4. Vida a fora/cotidiano & $7 \%$ & $5 \%$ & $6 \%$ \\
\hline C5. Física como conhecimento & $6 \%$ & $3 \%$ & $5 \%$ \\
\hline C6. Outras & $0 \%$ & $3 \%$ & $1 \%$ \\
\hline C7. Ilegível, não entendeu a pergunta & $0 \%$ & $0 \%$ & $0 \%$ \\
\hline C8. Não respondeu & $0 \%$ & $0 \%$ & $0 \%$ \\
\hline Total & $\mathbf{1 0 0} \%$ & $\mathbf{1 0 0} \%$ & $\mathbf{1 0 0} \%$ \\
\hline
\end{tabular}

A respeito da Física transposta ${ }^{2}$ para o Ensino Médio, os argumentos mais citados pelos licenciandos são os que remetem a essa disciplina como a que mais despertava o interesse, a curiosidade, a mais atraente, com a qual o aluno mais se identificava ou gostava de estudar. De acordo com esses argumentos, foi obtido um total de $62 \%$ das respostas. Foram encontrados, nesse grupo de respostas, argumentos 
que remetem a relações prazerosas estabelecidas pelos pesquisados com a Física secundarista; a Física aparece detentora de um forte sentido para os licenciandos, e fica quase evidente que eles gostavam dessa disciplina no Ensino Médio.

"Uma das disciplinas que mais achava interessante, e também a que mais me atraía a estudar" - 14/ITA $/ \mathrm{F} / 5^{\circ}$ ao $7^{\circ}{ }^{3}$

“Um talismã

Esse resultado é esperado, em tese, para um grupo de estudantes universitários que escolheram prolongar o estudo da Física na carreira acadêmica. Mas, sobremaneira, traz uma constatação importante para a pesquisa: 62\% dos licenciandos chegam à universidade altamente mobilizados para o estudo da Física, pois o sentido atribuído a essa disciplina do Ensino Médio está relacionado ao prazer, ao gozo.

Há, também, outras duas categorias de respostas que remetem a uma forte relação com o saber "Física". São as que mencionam o estudo da Física e o uso do seu corpo de conhecimentos na vida a fora $(6 \%)$, e as que citam a Física como importante para a obtenção e aumento do conhecimento dos alunos (5\%). Novamente nessas respostas, o estudo da Física tem um forte sentido que está relacionado à aplicação dessa ciência na vida dos então estudantes do Ensino Médio, hoje licenciandos em Física.

"Uma fonte de prazer e curiosidade com os fenômenos reais (dia a dia)" - 30/ ITA $/ \mathrm{M} / 8^{\circ}$ ao $10^{\circ}$.

Tabela 2: Resultados 04b

\begin{tabular}{|c|c|c|c|}
\hline \multicolumn{3}{|c|}{ Q4b - E a Matemática, era... } \\
\hline Argumentos Centrais & Homens & Mulheres & Total \\
\hline $\begin{array}{c}\text { C1. A que mais desperta o interesse ou a } \\
\text { curiosidade/que mais atrai/que o aluno se } \\
\text { identifica ou gosta de estudar }\end{array}$ & $47 \%$ & $33 \%$ & $43 \%$ \\
\hline $\begin{array}{c}\text { C2. Desinteresse, contradição ou } \\
\text { o aluno não gosta }\end{array}$ & $18 \%$ & $17 \%$ & $17 \%$ \\
\hline C3. Relações com a Física & $13 \%$ & $13 \%$ & $13 \%$ \\
\hline C4. Vida escolar & $9 \%$ & $23 \%$ & $13 \%$ \\
\hline C5. Relações lou a não existência destas) \\
com a vida a fora & $4 \%$ & $10 \%$ & $6 \%$ \\
\hline C7. A matemática e o corpo do seu conteúdo & $9 \%$ & $0 \%$ & $6 \%$ \\
\hline C6. Relações com a Universidade & $0 \%$ & $3 \%$ & $1 \%$ \\
\hline C8. Outras & $0 \%$ & $0 \%$ & $0 \%$ \\
\hline C9. Ilegível, não entendeu a pergunta & $0 \%$ & $0 \%$ & $0 \%$ \\
\hline C10. Não respondeu & $0 \%$ & $0 \%$ & $0 \%$ \\
\hline Total & $\mathbf{1 0 0 \%}$ & $\mathbf{1 0 0} \%$ & $\mathbf{1 0 0 \%}$ \\
\hline
\end{tabular}


Já em relação à Matemática, no questionamento Q4b, os alunos a citam como sendo a disciplina que mais desperta o interesse, a curiosidade, a que mais atrai, a que eles mais gostam de estudar em 43\% dos argumentos obtidos. Como se pode observar, houve um percentual menor para esse argumento em relação à Matemática quando essa disciplina é comparada à Física. Esse resultado não parece controverso, uma vez que é esperado que licenciandos em Física vejam essa disciplina como a que mais desperta o interesse. A Matemática também aparece com um percentual bastante significativo em relação à preferência dos estudantes. Para se estudar Física, o estudante precisa gostar de Matemática, mas esta não precisa ser a sua disciplina preferida.

"Também interessante, menos que a Física. Na verdade, as que eu mais gostava de estudar eram Física e Matemática” - 14/ITA/F/5 ao $7^{\circ}$.

Houve, ainda, $13 \%$ de respostas que relacionam a Matemática como importante para o estudo da Física. Para esse grupo de argumentos obtidos, a Matemática aparece como instrumento, ou como suporte fundamental, que possibilita o estudo da ciência física. A Matemática aparece com um sentido secundário. Na verdade, esse grupo demonstra que a Matemática é o mediador da sua relação com a Física; esta última ciência é o objetivo final a ser alcançado.

"O complemento da Física, um meio de chegar ao resultado esperado da forma esperada" $-07 / \mathrm{ITA} / \mathrm{M} / 1^{\circ}$ ao $4^{\circ}$.

"Um pré-requisito da Física" - 56/SC/F/5 ao $7^{\circ}$.

O percentual $(6 \%)$ que relaciona a Matemática e o seu uso vida a fora é bem inferior quando comparado ao obtido para a Física; também para esse grupo, a Matemática aparece desprovida de sentido por si só; o seu real sentido só se apresenta como ferramenta de compreensão dos conteúdos físicos.

“Cálculos sem muito sentido"-31/ITA/M/8 ao $10^{\circ}$.

Tanto para a Matemática quanto para a Física (13\% e 16\% do percentual total) houve argumentos nos quais se pode observar que essas são ciências citadas na vida escolar dos estudantes durante o Ensino Médio. Entram, nessa categoria, respostas que remetem a acontecimentos ocorridos à época escolar dos estudantes, advindos do estudo da Matemática e da Física, mas que não trazem indícios de estabelecimentos de uma relação forte de uma disciplina com a outra.

"Uma disciplina como todas as outras" - 09/ITA/M/1 ao 4".

Em relação à Física, no questionamento Q4a, as respostas mais inusitadas foram as que consideravam essa ciência como promotora de relações negativas nos alunos, o que totalizou 10\% dos pesquisados. Dessa maneira, pudemos concluir que um em cada dez licenciandos em Física chegou à universidade tendo estabelecido relações negativas com essa ciência, ou seja, desmobilizado para o curso.

"Um terror!" - 07/ITA $/ \mathrm{M} / 1^{\circ}$ ao $4^{\circ}$.

"Irrelevante"- 66/SC/M/5\% ao $7^{\circ}$.

Para a Matemática, houve $17 \%$ de argumentos nos quais os licenciandos citam o desinteresse, contradições ou assumem não gostar da disciplina. Tais argumentos, por apresentarem índices superiores em relação à Física, não provocaram 
tanta surpresa. Apesar de a Matemática ser muito utilizada para o ensino de Física no Ensino Médio, esse nível de dependência não se aproxima do exigido no nível de graduação, em que a "diferenciação" entre as duas disciplinas é praticamente inexistente. A Matemática é mais abstrata, a Física explica os fenômenos. Aponta-se esse fator como possível base da dificuldade de muitos estudantes nos períodos iniciais da licenciatura, pois alunos desmobilizados para a Matemática muito provavelmente terão sérias dificuldades no curso de Física.

"O satanás" - 07/ITA $/ \mathrm{M} / 1^{\circ}$ ao $4^{\circ}$.

\section{O QUE LEVOU OS LICENCIANDOS EM FÍSICA A ESCOLHER A LICENCIATURA}

Em seguida, foram apresentados, de maneira direta, questionamentos a respeito da motivação dos pesquisados no momento da escolha pela Física e pela licenciatura. Os resultados são expostos nas tabelas 3 e 4.

Tabela 3: Resultados 05a

\begin{tabular}{|c|c|c|c|}
\hline \multicolumn{4}{|c|}{ Q5a - Ao prestar o concurso vestibular, escolhi o curso de Física porque... } \\
\hline Argumentos Centrais & Homens & Mulheres & Total \\
\hline $\begin{array}{l}\text { C1. A que mais desperta o interesse ou a } \\
\text { curiosidade/que mais atrai/que o aluno se } \\
\text { identifica ou gosta de estudar }\end{array}$ & $19 \%$ & $33 \%$ & $23 \%$ \\
\hline C3. Relações estabelecidas na escola & $15 \%$ & $17 \%$ & $15 \%$ \\
\hline $\begin{array}{l}\text { C2. Gosto pela ciência/pelo estudo da } \\
\text { natureza/ funcionamento das coisas }\end{array}$ & $15 \%$ & $13 \%$ & $14 \%$ \\
\hline C4. Disciplina de exatas/ pela matemática & $11 \%$ & $17 \%$ & $12 \%$ \\
\hline C5. Mercado de trabalho/ futuro profissional & $13 \%$ & $3 \%$ & $10 \%$ \\
\hline C7. Por ser um curso noturno & $8 \%$ & $10 \%$ & $9 \%$ \\
\hline C6. Por falta de opções & $11 \%$ & $0 \%$ & $8 \%$ \\
\hline C9. Por querer ser professor/ físico & $3 \%$ & $7 \%$ & $4 \%$ \\
\hline C8. Pela facilidade de ingresso & $4 \%$ & $0 \%$ & $3 \%$ \\
\hline C10. Outras & $0 \%$ & $0 \%$ & $0 \%$ \\
\hline C11. Ilegível, não entendeu a pergunta & $1 \%$ & $0 \%$ & $1 \%$ \\
\hline C12. Não respondeu & $1 \%$ & $0 \%$ & $1 \%$ \\
\hline Total & $100 \%$ & $100 \%$ & $100 \%$ \\
\hline
\end{tabular}

$\mathrm{Na}$ soma das categorias em que os pesquisados dizem ter escolhido o curso pelo fato de a Física escolar ser a disciplina que mais despertava o interesse, 
juntamente à categoria que representa as relações positivas estabelecidas com a Física escolar, há 38\% de licenciandos afirmando que a escolha pela Física como carreira acadêmica teve ligação direta com a Física do Ensino Médio. Observa-se, então, com clareza, a relação entre o estabelecimento de relações positivas com a Física, que se originaram na escola, e a escolha pela Física como carreira acadêmica na universidade.

No que diz respeito aos argumentos que remetem ao gosto pela ciência/ pelo estudo da natureza/funcionamento das coisas, houve um percentual de $52 \%$ de alunos que afirmaram que chegam à universidade mobilizados para a Física e também para a Matemática, pois em 12\% das respostas surgem argumentos que justificam a escolha do curso de Física devido a este pertencer à área de exatas. Ou seja, confirmam-se os resultados obtidos para os questionamentos anteriores, que tratam da Física e da Matemática escolar.

Quando perguntados a respeito da opção pela licenciatura, as respostas podem ser visualizadas na tabela Q4.

Tabela 4: Resultados 05b

\begin{tabular}{|c|c|c|c|}
\hline \multicolumn{4}{|c|}{ Q5b - E o que me levou a optar pelo curso de licenciatura... } \\
\hline Argumentos Centrais & Homens & Mulheres & Total \\
\hline $\begin{array}{c}\text { C1. Por gostar/ter vontade de ser professor } \\
\text { (a) / de ensinar/ de transmitir conhecimento }\end{array}$ & $33 \%$ & $48 \%$ & $38 \%$ \\
\hline C2. Pelo mercado de trabalho & $31 \%$ & $19 \%$ & $28 \%$ \\
\hline $\begin{array}{c}\text { C6. Por gostar de Física/exatas/ } \\
\text { por aptidão/ curiosidade }\end{array}$ & $12 \%$ & $10 \%$ & $11 \%$ \\
\hline C4. Por influência de alguém/ algo & $6 \%$ & $16 \%$ & $7 \%$ \\
\hline C3. Por falta de opção & $9 \%$ & $3 \%$ & $3 \%$ \\
\hline C5. Pelo bacharelado & $3 \%$ & $3 \%$ & $1 \%$ \\
\hline C7. Outros & $1 \%$ & $0 \%$ & $1 \%$ \\
\hline C8. Não respondeu & $100 \%$ & $100 \%$ & $\mathbf{1 0 0} \%$ \\
\hline Total & $3 \%$ & $0 \%$ & $2 \%$ \\
\hline
\end{tabular}

O que os resultados dizem é que a maioria dos pesquisados, 38\%, estabelece uma relação positiva com o futuro exercício da docência ainda antes do ingresso na universidade. Porém, são encontrados poucos argumentos que permitem verificar por que e de que forma essa relação foi estabelecida. Nessa categoria, os licenciandos dizem que gostam da profissão de professor, que gostam de lecionar, de passar o conhecimento que adquirem, mas não especificam o que os motivou para tanto. E, diferente da relação estabelecida com a Física, analisada no 
questionamento anterior, não citam a escola como sendo o lugar que deu origem a essa relação.

"Sempre tive vontade de ser professora" - 01/ITA/F/1" ao 4".

"Gostar de dar aulas, a profissão de professor é uma das mais gratificantes" - 44/ $\mathrm{SC} / \mathrm{M} / 1^{\circ}$ ao $4^{\circ}$.

O mercado de trabalho aparece como argumento mais forte em relação ao questionamento que remete à licenciatura (28\%) quando comparado ao que remete à escolha pelo curso de Física (10\%). Os pesquisados mostram-se conscientes da necessidade que o mercado de trabalho possui em relação a profissionais ligados ao ensino de Física, o que se torna, para esse grupo, o principal fator mediador da escolha pela licenciatura. Para esse grupo, o ensinar tem um sentido que é secundário. A mobilização para o ensinar existe, mas se mostra mais fraca, quando comparada às respostas dadas pelo grupo analisado anteriormente.

"Sinceramente, licenciatura em Física, pelo mercado de trabalbo"-30/ITA/M/8 ao $10^{\circ}$.

"O mercado de trabalho para nosso estado oferece mais oportunidades"- 58/SC/ $\mathrm{F} / 5^{\circ}$ ao $7^{\circ}$.

Porém, surgem argumentos nas respostas obtidas, para ambos os questionamentos, que remetem à escolha do curso por falta de opção. O percentual obtido nessa categoria foi praticamente o mesmo. O que se pode afirmar é que para esse grupo de pesquisados (entre 7\% e 8\%), a mobilização para o ensino de Física é extremamente fraca, ou praticamente inexistente. O ensinar carece, quase que totalmente, de sentido para esse grupo de licenciandos. Análise idêntica pode ser feita para as categorias que remetem à escolha pelo bacharelado (tabela 4), por ser um curso noturno e pela facilidade de ingresso (tabela 3). Esses resultados podem explicar por que há estudantes de Física na universidade que não gostam dessa ciência.

"Sinceramente, porque era um curso noturno em Itabaiana, pois não tinha condiçoes de estudar em Aracaju” - 04/ITA/M/1 ao 4".

"Tinha poucas opções, então fui enfrentar o desafio" - 07/ITA/M/1º ao $4^{\circ}$.

\section{OS LICENCIANDOS EM FÍSICA: SUAS EXPECTATIVAS ANTES E DEPOIS DO INÍCIO DA GRADUACุÃO}

De acordo com a teoria da relação com o saber, a relação com os saberes ou com determinado tipo de saber é uma relação consigo mesmo, com os outros e com o mundo. Nos questionamentos propostos a seguir, pretende-se entender a relação estabelecida pelo licenciando com o ensinar, focalizando o conjunto de expectativas que o pesquisado idealizou para o curso antes e após o ingresso na universidade. Além disso, investigou-se de que forma essas relações influenciam (ou influenciaram) a relação do licenciando com o ensinar. Os resultados obtidos seguem nas tabelas 5 e 6 . 
Tabela 5: Resultados 06a

\begin{tabular}{|c|c|c|c|}
\hline \multicolumn{4}{|c|}{ Q6a - Em relação ao curso, as minhas expectativas antes do início da graduação eram.. } \\
\hline Argumentos Centrais & Homens & Mulheres & Total \\
\hline C4. Dificuldades do curso & $20 \%$ & $35 \%$ & $24 \%$ \\
\hline C1. Expectativas positivas & $21 \%$ & $27 \%$ & $23 \%$ \\
\hline C2. Exercício da docência no Ensino Médio & $15 \%$ & $12 \%$ & $14 \%$ \\
\hline $\begin{array}{l}\text { C5. Vida acadêmica/obtenção } \\
\text { de conhecimento }\end{array}$ & $18 \%$ & $4 \%$ & $14 \%$ \\
\hline C8. Incerteza ou ausência de expectativas & $10 \%$ & $4 \%$ & $8 \%$ \\
\hline C3. Aprendizagem de Física & $7 \%$ & $4 \%$ & $6 \%$ \\
\hline C6. Mercado de trabalho & $5 \%$ & $8 \%$ & $6 \%$ \\
\hline $\begin{array}{l}\text { C7. Prazer em aprender o curso } \\
\text { por sua dificuldade }\end{array}$ & $0 \%$ & $8 \%$ & $2 \%$ \\
\hline c9. Outras & $0 \%$ & $0 \%$ & $0 \%$ \\
\hline C10. Ilegível, não entendeu a pergunta & $0 \%$ & $0 \%$ & $0 \%$ \\
\hline C11. Não respondeu & $5 \%$ & $0 \%$ & $3 \%$ \\
\hline Total & $100 \%$ & $100 \%$ & $100 \%$ \\
\hline
\end{tabular}

Há, para esse questionamento, a obtenção do conhecimento de maneira vaga, sem citar especificamente a docência. Os conhecimentos aparecem especificados, somente em relação aos conteúdos físicos, totalizando $20 \%$ dos argumentos obtidos. Esse grupo de pesquisados cita o saber, de maneira geral ou em relação à Física especificamente, sem citar a docência. Além disso, ainda que de maneira vaga, sem maior precisão, 23\% das respostas obtidas remetem a expectativas positivas em relação à licenciatura em Física antes dos pesquisados iniciarem o curso na universidade.

"A satisfação de uma possivel compreensão e explicação melhor sobre o mundo" - 09/ ITA $/ \mathrm{M} / 1^{\circ}$ ao $4^{\circ}$.

"As melhores possiveis" - 56/SC/F/5 ao $7^{\circ}$.

$14 \%$ dos argumentos obtidos remetem especificamente a expectativas em relação à docência. Nesse grupo há, claramente, indicativos de mobilização para o ensinar. O sentido da graduação, antes mesmo do ingresso desses licenciandos, já era o ensino de Física.

"Que a universidade proporcionasse subsidios capazes de me fazer um bom professor" $-06 / \mathrm{ITA} / \mathrm{M} / 1^{\circ}$ ao $4^{\circ}$.

"Obter um bom conhecimento para levar aos alunos do Ensino Médio ao concluir a graduação.” - 75/SC/M/5a a $7^{\circ}$.

$23 \%$ reconhecem que o curso que estava por vir necessitaria de trabalho e dedicação para a obtenção do sucesso na universidade. 
"Era que eu deveria estudar muito" - 64/SC/M/5 ao $7^{\circ}$.

Há, ainda, aqueles que dizem não possuir expectativas, o que representou um total de $8 \%$ das respostas obtidas. São alunos mais fracos pedagogicamente, pois não apresentam pretensão alguma pelo curso.

Mas, ao serem questionados sobre o que pensam do curso agora que o estão cursando, houve uma mudança bastante significativa em relação às expectativas iniciais, conforme demonstra a tabela 6 .

Tabela 6: Resultados Q6b

\begin{tabular}{|c|c|c|c|}
\hline \multicolumn{4}{|c|}{ Q6b - E agora, em relação ao que esperava do curso, penso que... } \\
\hline Argumentos Centrais & Homens & Mulheres & Total \\
\hline C1. Críticas ao curso de licenciatura & $22 \%$ & $28 \%$ & $24 \%$ \\
\hline $\begin{array}{c}\text { C2. Mudanças em relação às } \\
\text { expectativas iniciais }\end{array}$ & $20 \%$ & $21 \%$ & $20 \%$ \\
\hline $\begin{array}{c}\text { C3. Atendimento/superação das } \\
\text { expectativas iniciais }\end{array}$ & $18 \%$ & $10 \%$ & $16 \%$ \\
\hline C5. Necessidade de estudo, esforço & $12 \%$ & $17 \%$ & $13 \%$ \\
\hline C6. Respostas contraditórias & $7 \%$ & $3 \%$ & $6 \%$ \\
\hline C8. Futuro profissional & $2 \%$ & $14 \%$ & $6 \%$ \\
\hline C4. Futuro acadêmico & $3 \%$ & $7 \%$ & $14 \%$ \\
\hline C7. Desejo de aumentar conhecimentos & $5 \%$ & $0 \%$ & $3 \%$ \\
\hline C9. Conclusão do curso & $3 \%$ & $0 \%$ & $2 \%$ \\
\hline C10. Outras & $2 \%$ & $0 \%$ & $1 \%$ \\
\hline C11. Ilegível, não entendeu a pergunta & $2 \%$ & $0 \%$ & $1 \%$ \\
\hline C12. Não respondeu & $5 \%$ & $0 \%$ & $3 \%$ \\
\hline Total & $\mathbf{1 0 0} \%$ & $\mathbf{1 0 0} \%$ & $\mathbf{1 0 0 \%}$ \\
\hline
\end{tabular}

Há, em 24\% das respostas dos alunos pesquisados, argumentos que evocam críticas, ou seja, que nos indicam algum tipo de insatisfação em relação ao curso. Esses acadêmicos sentem a necessidade de uma maior valoração da licenciatura, conforme indicam suas próprias respostas.

"A maioria, on seja, quase tudo que vejo aqui não vai servir para dar aula" - 23/ ITA $/ \mathrm{M} / 5^{\circ}$ ao $7^{\circ}$.

'Não é só para ensinar que estamos na universidade, mas também para vermos coisas que não servirão para a gente, como as disciplinas voltadas para o bacharelado. Acho que deveria ter sido mais na área de educação, como dar aulas." - 25/ITA/F/8 ao $10^{\circ}$.

"Infelizmente o curso prepara o aluno para ser cientista e não para ser um bom professor na área de educação, para lecionar no Ensino Médio”- 75/SC/M/5a ao $7^{\circ}$.

Aparece, ainda, um percentual de $20 \%$ de respostas que indicam mudanças em relação às expectativas iniciais a respeito do curso de licenciatura em Física 
ofertado pela Universidade Federal de Sergipe. Observou-se que a maioria dos argumentos obtidos remete a uma dificuldade encontrada no curso acima do que era esperada pelos licenciandos antes do ingresso na universidade.

Alguns dos licenciandos pesquisados (16\%) dizem-se satisfeitos ou surpreendidos positivamente pelo curso. Como se vê, esse grupo apresenta-se, em termos de percentuais, bem inferior aos que sugerem insatisfação ou críticas. Mas, pode-se verificar que para eles, a licenciatura ofertada influencia de maneira positiva o fortalecimento de suas relações com o ensinar.

Reforça-se a necessidade de esforço, porém, há índices menores para o período após o início do curso (13\%). Futuro profissional, como em quase todos os questionamentos propostos, aparece como argumento citado pelos pesquisados. Embora esses dois últimos questionamentos específicos tenha apresentado um percentual pequeno ( $6 \%$ em ambos), o futuro profissional é recorrente nas respostas e representa um dos maiores motivos da escolha pela licenciatura. Os pesquisados, quando falam de suas expectativas após o início do curso, citam o futuro acadêmico em 4\% das respostas obtidas.

\section{DO QUE, SEGUNDO OS LICENCIANDOS, A LICENCIATURA EM FÍSICA OS TORNA CAPAZES}

Tabela 7: Resultados 07

\begin{tabular}{|c|c|c|c|}
\hline \multicolumn{2}{|c|}{ Q7 - Com a graduação em licenciatura em Física eu posso... } \\
\hline Argumentos Centrais & Homens & Mulheres & Total \\
\hline C1. Transmissão do conhecimento & $24 \%$ & $27 \%$ & $25 \%$ \\
\hline C6. Futuro acadêmico & $9 \%$ & $27 \%$ & $15 \%$ \\
\hline C3. Exercício da docência, especificado & $15 \%$ & $14 \%$ & $14 \%$ \\
\hline $\begin{array}{c}\text { C2. Desejo de contribuir para a melhoria do } \\
\text { ensino de Física }\end{array}$ & $9 \%$ & $5 \%$ & $8 \%$ \\
\hline C4. Futuro/Exercício profissional & $8 \%$ & $5 \%$ & $7 \%$ \\
\hline C5. Prazer em ensinar & $4 \%$ & $8 \%$ & $5 \%$ \\
\hline C7. Compreensão do mundo/ Cotidiano & $4 \%$ & $5 \%$ & $5 \%$ \\
\hline C8. Desejo de não exercer a docência & $8 \%$ & $0 \%$ & $5 \%$ \\
\hline C10. Melhoria financeira & $4 \%$ & $3 \%$ & $4 \%$ \\
\hline C11. Alcance de sonhos/ Ir além & $3 \%$ & $5 \%$ & $4 \%$ \\
\hline C9. Desejo de adquirir conhecimento & $4 \%$ & $0 \%$ & $3 \%$ \\
\hline C12. Outras & $0 \%$ & $0 \%$ & $0 \%$ \\
\hline C13. Ilegível, não entendeu a pergunta & $0 \%$ & $0 \%$ & $0 \%$ \\
\hline C14. Não respondeu & $7 \%$ & $0 \%$ & $5 \%$ \\
\hline Total & $\mathbf{1 0 0} \%$ & $\mathbf{1 0 0} \%$ & $\mathbf{1 0 0 \%}$ \\
\hline
\end{tabular}


O exercício da docência é citado em 14\% dos argumentos. Somando essa resposta com o percentual de $8 \%$, em que os licenciandos demonstram o interesse em contribuir para a melhoria do ensino de Física e com os $25 \%$ de respostas que citam a transmissão do conhecimento, embora de maneira não especificada à docência, há um número de $48 \%$ do total dos pesquisados que indicam um possível exercício da docência a partir da graduação em licenciatura em Física. Com isso, pode-se concluir, a partir desses resultados e em comparação com os obtidos anteriormente, é que, apesar de existirem críticas, ressalvas e discordâncias em relação ao curso oferecido pela universidade, quase a metade dos licenciandos acreditam que de posse da graduação eles podem, sim, exercer a docência.

"Ensinar tudo que aprendi ao longo do curso, e contribuir para formar novos cidadãos" $-23 / \mathrm{ITA} / \mathrm{M} / 5^{\circ}$ ao $7^{\circ}$.

'Lecionar Física, e através dela posso construir nos meus alunos um motivo para se dedicar aos estudos, provocando a vontade de aprender" - 79/SC/M/8 ao $10^{\circ}$.

Porém, o grupo que apresenta o maior nível de mobilização para o ensinar aparece em somente $5 \%$ das respostas obtidas. Nelas, há argumentos que remetem a uma relação prazerosa estabelecida pelo licenciando com o ensinar. Para esse grupo, o sentido em ensinar repousa sobre o ato de ensinar em si, não existe um outro motivo que media essa relação.

"Ir para uma sala de aula, fazer aquilo que gosto de fazer, e posso também ganhar dinheiro" - 09/ITA/M/1 ${ }^{\circ}$ ao $4^{\circ}$.

Observa-se, acima, um exemplo claro do que se quer dizer. O aluno evoca, em sua resposta, primeiramente, o gosto pelo exercício da docência. A atividade em si é carregada de sentido para ele; mas, isso não impede que ele tenha pretensões de "ganhar dinheiro"; afinal, exercerá uma atividade profissional remunerada, o que aparece como motivo secundário na mobilização. Em outras palavras, o licenciando afirma: "sinto prazer em exercer a licenciatura e, a partir disto, posso ganhar dinheiro”.

Respostas que relacionam a graduação ao futuro, ao exercício profissional, juntamente às que evocam melhoria financeira, aparecem em

$11 \%$ das respostas obtidas. Novamente, reafirma-se a recorrência desses argumentos nas respostas obtidas nesta pesquisa.

"Ter um emprego." - 33/SC/F/1 ao $4^{\circ}$.

O futuro acadêmico aparece em 15\% dos resultados. Ele, na maioria dos casos, está colocado de forma geral, não aparece como sendo um interesse do aluno em cursar uma pós-graduação em ensino de Física. A ausência dessa especificação nas respostas obtidas na pesquisa não permite afirmar que esses alunos não estão interessados em se especializarem para a atuação docente.

'Fazer uma pós-graduação na área de Física e desenvolver pesquisas relacionadas com esta" - $75 / \mathrm{SC} / \mathrm{M} / 5^{\circ}$ ao $7^{\circ}$.

A compreensão do mundo, do cotidiano, bem como o desejo de aquisição de conhecimento de maneira geral também aparecem nos argumentos obtidos, somando um total de 8\% das respostas. Os estudantes citam, ainda, a graduação 
como sonho alcançado (4\%), o que confirma os resultados obtidos no primeiro bloco de perguntas do questionário.

$5 \%$ dos licenciandos demonstram claramente não estarem interessados no exercício da docência. Para esse grupo de pesquisados, a licenciatura servirá como base para cursar o bacharelado, outros cursos de exatas ou, tão somente, para a obtenção do diploma de nível superior.

\section{DIFERENC̣AS EM RELAC̣ÃO AO SEXO}

Quando são analisadas as relações estabelecidas pelos licenciandos com a Física escolar, observa-se que praticamente não há divergência entre os rapazes e as moças pesquisadas. Já em relação à Matemática, percebe-se que o percentual feminino para as respostas que evocam o interesse, a curiosidade, cai um pouco em relação ao percentual de respostas dadas pelos pesquisados do sexo masculino. Com isso, percebe-se que, apesar de ambos os sexos apresentarem uma mobilização próxima em números para a Física, os rapazes apresentam-se mais mobilizados para a Matemática escolar que as moças.

Há uma diferença, também, em relação aos argumentos que evocam a relação dos homens com a Matemática na vida escolar, sendo que as mulheres apresentam um percentual muito maior para essa categoria. A maioria dos argumentos consideram a Matemática como uma disciplina como outra qualquer, e ainda mencionam a falta de professores e situações escolares específicas que indicam relações com a Matemática.

Em relação à escolha pela Física na graduação, vê-se uma queda em ambos os sexos. Essa queda, porém, é muito mais acentuada em relação aos rapazes. Eles passam a citar outros argumentos que justificam sua escolha, como o mercado de trabalho, o que com frequência é bem menor em relação às mulheres. Os homens afirmam, ainda, que a escolha pelo curso deve-se à ausência de opções e pela facilidade de ingresso (não houve mulheres que citaram esses argumentos).

Já em relação à escolha pela licenciatura, o gosto, a vontade de ser professor e o mercado de trabalho foram os argumentos mais citados pelos dois sexos. Porém, os homens apresentam índices muito próximos para essas duas categorias de respostas, demonstrando quase uma igualdade em relação a essas duas motivações. As mulheres apresentam argumentos que justificam a escolha pela licenciatura que tendem muito mais para o gosto, para a vontade de ser professora, em detrimento ao mercado de trabalho.

As mulheres esperam mais dificuldades em relação ao curso antes de entrar na graduação, mas também possuem mais expectativas positivas em relação à licenciatura que os homens. Além disso, apresentam um novo argumento muito interessante: o prazer em aprender o curso por sua dificuldade.

Observa-se, também, que apesar de os rapazes se preocuparem mais em relação ao mercado de trabalho antes do ingresso na universidade, as moças 
apresentam índices maiores quando se fala a respeito do futuro, sendo ele profissional ou acadêmico. Além disso, elas apresentam maiores índices em relação ao prazer pelo futuro exercício da docência em Física do que os rapazes.

\section{PRINCIPAIS CONCLUSÕES: AFINAL DE CONTAS, O QUE LEVOU OS PESQUISADOS A CURSAR UMA LICENCIATURA EM FÍSICA?}

Vê-se claramente que a maioria dos licenciandos chega à universidade atribuindo à Física apresentada no Ensino Médio um forte sentido, sendo quase que evidente que eles gostavam dessa disciplina. Concluiu-se que escolhem a Física como carreira acadêmica universitária devido ao estabelecimento de relações positivas com essa disciplina, que se originaram na escola. A Matemática também aparece em um percentual bastante significativo em relação à preferência dos estudantes, também se apresentando como mediadora da escolha pela Física na universidade (porém, com um percentual inferior ao da Física).

Em relação à escolha pela licenciatura, os resultados mostram que a maioria dos pesquisados estabelece uma relação positiva com o futuro exercício da docência antes do ingresso na universidade; porém, não deixam claro, em suas respostas, por que e de que forma essa relação foi estabelecida, e não apresentam tantos argumentos quanto os apresentados para a escolha pela Física (que nesta pesquisa aparece de forma mais justificada que a escolha pela licenciatura).

Destaca-se, também, outro forte fator mediador entre os licenciandos e a escolha pela licenciatura em Física: o mercado de trabalho. Isso pode ser verificado quando este aparece como argumento mais forte no questionamento que remete à licenciatura, em detrimento ao que remete à escolha pela Física, sendo que muitos dos pesquisados mostraram-se conscientes da demanda que o mercado de trabalho possui em relação a professores dessa disciplina.

Além disso, observa-se que apesar de existirem críticas, ressalvas e discordâncias em relação ao curso oferecido pela universidade, boa parte dos futuros professores de Física acreditam que, com a graduação, podem exercer a docência. Porém, respostas que relacionam a escolha pela licenciatura ao gozo, ao prazer, aparecem em pequeno percentual nos resultados obtidos.

Chama atenção, também, que alguns licenciandos indicam ter escolhido o curso por falta de opção, pela facilidade de ingresso, etc. Para esse grupo de pesquisados, a mobilização para o ensino de Física é extremamente fraca, ou praticamente inexistente. O ensinar carece quase que totalmente de sentido para eles. Essa parece ser, também, uma das explicações para o fato de existirem, segundo os resultados obtidos, licenciandos em Física que demonstram não gostar nem dessa disciplina, nem da Matemática. 


\section{NOTAS}

${ }^{1}$ Education, Socialisation et Collectivités Locales, nome francês da equipe liderada por Bernard Charlot que realizava pesquisas relacionadas à relação dos alunos com o saber que se iniciaram em 1987, na Universidade de Paris 8, França.

${ }^{2}$ Refere-se ao conceito de Chevallard (1991) de transposição didática, que remete à transformação do saber sábio ao saber a ser ensinado. No caso da escola, trata-se da transformação do conhecimento científico em conhecimento escolar, para que possa ser ensinado pelos professores e aprendido pelos alunos.

${ }^{3}$ Essa é uma classificação adotada na pesquisa para os questionários. No caso acima, refere-se ao questionário $\mathrm{n}^{\circ} 14$, Campus Itabaiana (ITA), sexo feminino (F), aluno cursando entre o $5^{\circ}$ e $7^{\circ}$ período $\left(5^{\circ}\right.$ ao $\left.7^{\circ}\right)$. As citações na sequência podem ser analogamente identificadas pelos seguintes códigos: campus São Cristóvão (SC); sexo masculino (M); cursando entre o $1^{\circ}$ e $4^{\circ}$ período $\left(1^{\circ}\right.$ ao $\left.4^{\circ}\right)$; cursando entre o $8^{\circ}$ e $10^{\circ}$ período $\left(8^{\circ}\right.$ ao $\left.10^{\circ}\right)$.

\section{REFERÊNCIAS}

CHARLOT, B. Da relação com o saber: elementos para uma teoria. Artmed Editora: Porto Alegre, 2000. - A noção de relação com o saber: bases de apoio teórico e fundamentos antropológicos. In: CHARLOT, Bernard (Org.). Os jovens e o saber: perspectivas mundiais. Porto Alegre: Artmed, 2001.

. Relação com o saber, formação dos professores e Globalização: questões para a educação hoje. Porto Alegre: Artmed, 2005.

- A Relação com o saber nos meios populares - Uma investigação nos liceus profissionais de subúrbio. Legis Editora: Cidade do Porto, Portugal, 2009.

CHEVALLARD, Y. La transposición didáctica: del saber sabio al saber enseñado. Editora Aique: Buenos Aires, 1991.

FEITOSA, L. D. Os licenciandos em física da UFS e as suas relações com o ensinar - Uma investigação a partir da Teoria da Relação com o Saber. Dissertação (Mestrado) - Universidade Federal de Sergipe, São Cristóvão/SE, 2012.

SILVA, V. A. Por que e para que aprender a matemática? São Paulo: Cortez, $1^{\text {a }}$ Edição, 2009.

Data de Aprovação: 19/05/2013

Data do Recebimento: 22/02/2013

Data da Versão Final: 05/07/2013 